ELUA

ISSN 2171-6692

Núm. 35, 2021, págs. 337-342

https://doi.org/10.14198/ELUA2021.35.18

\title{
ALCALÁ VENCESLADA, ANTONIO (2019). VOCABULARIO ANDALUZ (ILUSTRADO), EDICIÓN FACSIMILAR CON ESTUDIO PRELIMINAR DE MANUEL GALEOTE Y PRÓlOGO DE PEDRO ÁlVAREZ DE MI- RANDA. LAUSANA/ZARAGOZA. SOCIEDAD SUIZA DE ESTUDIOS HISPÁNICOS/PÓRTICO [HISPANICA HELVETICA, 31], (496 PÁGINAS., ISBN: 978-84-7956-198-7).
}

\author{
David Prieto García-Seco \\ Universidad de Murcia, España \\ davidprieto@um.es \\ https://orcid.org/0000-0002-7417-2791
}

Si bien es cierto que la presencia de regionalismos se remonta al inicio mismo de la lexicografía académica, no será sino en la edición de 1925 del diccionario vulgar de la Real Academia Española cuando se comience a apostar decididamente por la incorporación de dialectalismos (Garriga Escribano y Rodríguez Ortiz, 2007: 270 y ss.; cfr. Ahumada Lara, 2000). En la Advertencia de la 15. a edición del DRAE (1925: VII) se indicaba: «Ha concedido también atención muy especial a los regionalismos de España y de América que se usan entre la gente culta de cada país, voces que estaban muy escasamente representadas en las ediciones anteriores». Este hecho - explica la Academia - fue uno de los factores que justificaron la sustitución del adjetivo castellana por española en el título de la obra: «Como consecuencia de esta mayor atención consagrada a las múltiples regiones lingüísticas, aragonesa, leonesa e hispanoamericana, que integran nuestra lengua literaria y culta, el nuevo Diccionario adopta el nombre de "lengua española" en vez del de "castellana" que antes estampó en sus portadas» (ibíd.: VIII). El deseo de aumentar el caudal de dialectalismos del diccionario vulgar empujó a la Academia a promover, mediante la convocatoria de premios, la recolección de léxicos regionales. Así, el 2 de julio de 1930 la Gaceta de Madrid publicó la convocatoria del premio de la Fundación Conde de Cartagena. Uno de los cuatro temas que salieron a concurso fue el siguiente: "Vocabulario de una región de habla española», cuyas bases específicas de la convocatoria decían así:

1. ${ }^{\circ}$ Voces nuevas que no estén en el Diccionario.

2. ${ }^{\circ}$ Voces que estando en el Diccionario tengan acepción distinta de la que el Diccionario registra.

Para citar esta reseña: Prieto García-Seco, David (2021). Antonio Alcalá Venceslada: Vocabulario andaluz (ilustrado), edición facsimilar con estudio preliminar de Manuel Galeote y prólogo de Pedro Álvarez de Miranda. Lausana/Zaragoza, Sociedad Suiza de Estudios Hispánicos/Pórtico [Hispanica Helvetica, 31] ELUA, 35: 337-342. https://doi.org/10.14198/ELUA2021.35.18

(C) 2021 David Prieto García-Seco 
3. Se recomienda especial atención a las voces de artes, industrias, oficios y faenas agrícolas, etc., etc., de la región.

$4 .^{\circ}$ Las voces habrán de definirse con exactitud e ir acompañada la definición con ejemplos auténticos de frases en las que entre la palabra definida.

5. ${ }^{\circ}$ Cuando se utilicen fuentes literarias, deberán aducirse como autoridades los textos tomados de dichas fuentes.

6. ${ }^{\circ}$ Sería de desear que en las voces técnicas las definiciones estuviesen acompañadas de dibujos o fotografías de los objetos definidos.

(Gaceta de Madrid, n. ${ }^{\circ}$ 183, 2 de julio de 1930, p. 75a).

Como es bien sabido, Antonio Alcalá Venceslada (Andújar, 1883-Jaén, 1955) concurrió a dicho premio con su Vocabulario andaluz y fue galardonado. La concesión del premio (con una dotación de 10000 pesetas) se hizo pública en abril de 1933 y el libro se publicó entre 1933 y 1934 (la primera fecha figura en la portada y la segunda, en el colofón). La Academia volvió a convocar el mismo premio y Alcalá Venceslada se presentó nuevamente. Pasada la Guerra Civil, en noviembre de 1941 la Academia falló el premio y volvió a concedérselo al lexicógrafo iliturgitano. Poco antes de la concesión del segundo premio, en junio, Alcalá Venceslada había sido nombrado académico correspondiente por Andalucía (cfr. Ahumada Lara, 1986). Aquel trabajo premiado en el segundo concurso, que contenía un caudal léxico noblemente superior al de la compilación de 1933-34 («17 547 entradas aparecen en el VA (1951), frente a las 4245 de la edición anterior», Carriscondo Esquivel, 2004: 108), se convirtió diez años más tarde en la segunda edición del Vocabulario andaluz (1951).

La Academia, en efecto, fomentó la compilación de repertorios léxicos de regionalismos con el objeto de servirse de ellos posteriormente para su propio diccionario, bien incluyendo nuevas voces o acepciones, bien mejorando distintos aspectos de las entradas recogidas. Ahora bien, llama la atención que, una vez publicado el Vocabulario andaluz, la Corporación madrileña apenas aprovechara los materiales léxicos que le proporcionaba aquel primer repertorio. Carriscondo Esquivel estudió la influencia del Vocabulario andaluz en las ediciones de 193639 y 1947 del $D R A E$ y comprobó que la aportación del primer trabajo de Alcalá Venceslada a los diccionarios académicos fue muy pequeña: «A pesar de la ya conocida pretensión académica de impulsar la creación de vocabularios dialectales, no se produce una incorporación masiva de los datos ofrecidos por el VA (1934), por lo menos en las ediciones del DRAE (1936/47)» (Carriscondo Esquivel, 2001: 484; sobre la influencia de Vocabulario andaluz de 1951 en los diccionarios académicos, acúdase a Carriscondo Esquivel, 2004).

$$
* * *
$$

El Vocabulario andaluz, como se ha dicho, se publicó por primera vez entre 1933 y 1934 y, al cabo de diecisiete años, vio la luz su segunda edición, publicada por la Academia. Además de los distintos estudios de que ha sido objeto, prueba del interés que ha despertado el Vocabulario andaluz son las diversas ediciones realizadas hasta la fecha. En 1980 la editorial Gredos reprodujo la segunda edición. Al cabo de unos años, en 1998, Ahumada Lara nos ofreció una edición facsimilar, también de la edición de 1951, con un valioso anexo de complementos inéditos. Un año más tarde, en 1999, volvió a aparecer una nueva edición, en esta ocasión patrocinada por el diario El Mundo. Andalucía. Estas tres ediciones se basaron, como cabía esperar, en la de 1951, puesto que es la última y más completa en vida del autor. 
Sin embargo, hasta hoy no se había vuelto a publicar la versión primigenia del Vocabulario. La edición que nos presenta Galeote, y que aquí reseñamos, reproduce facsimilarmente aquel primer repertorio de los años treinta.

Encabeza la edición un estudio preliminar (pp. 11-55), dividido en cuatro apartados, en los que se resumen las aportaciones más notables de la crítica en torno al Vocabulario y se añaden algunas consideraciones del editor: 1) INTRODUCCIÓN, 2) El REPERTORIO DiALECtal ilustrado por Alcalá Venceslada, 3) Lemas con ilustraciones del Vocabulario y 4) Conclusiones (además de la bibliografía manejada). En el primer apartado (pp. 13-14) se presenta una breve semblanza biográfica del autor del Vocabulario andaluz y se recogen algunos datos sobre la vinculación de Alcalá Venceslada con la Academia.

En el segundo apartado (pp. 15-33) Galeote comienza expresando qué le ha llevado a reproducir la primera edición del Vocabulario andaluz: «Hoy es una edición muy rara y de difícil consulta, por lo que nos hemos decidido a reimprimirla en edición facsimilar por su interés científico fundamentalmente» (p. 15), y poco después añade: «Resulta difícil en la actualidad consultar ejemplares de aquella edición. Casi todos los investigadores acuden a la segunda edición (Madrid, 1951), que es la más extensa y difundida, y prescinden de estudiar la que se editó en Andújar, la única con ilustraciones (1934), a pesar de todas sus carencias» (p. 17). Seguidamente, se tratan muy diversas cuestiones en torno al Vocabulario andaluz: se recuerdan algunos antecedentes en el intento de inventariar el léxico andaluz, como, por ejemplo, las Voces andaluzas de Toro y Gisbert (reeditadas por el mismo Galeote, con un estudio preliminar, en 2007); se alude al interés de la Academia por fomentar la publicación de vocabularios regionales; se habla de las limitaciones del método lexicográfico de Alcalá Venceslada en relación, principalmente, con las citadas bases del Premio Conde de Cartagena; se menciona la aportación del Vocabulario al diccionario de la Academia; etc. Galeote, sobre todo, enumera algunas de sus «limitaciones estructurales», entre las que se encuentran las siguientes: «se combinan criterios fonéticos con alfabéticos en la lematización (por ejemplo, achulejo 'hacha pequeña' se escribe $\sin h$ - inicial para reflejar que no se aspira la consonante en la pronunciación)», «faltan marcas lexicográficas y otras se usan con bastante arbitrariedad» o «es necesario acudir al DMILE [= Diccionario manual de la Academia] para entender las abreviaturas, que tampoco se relacionan en un apartado» (p. 22).

En relación, asimismo, con las limitaciones del Vocabulario, se dedica un subapartado (2.1.) al problema al que tuvo que enfrentarse, y no supo resolver, Alcalá Venceslada a la hora de lematizar las voces inventariadas, puesto que se sirvió de los grafemas convencionales del español para transcribirlas fonéticamente, tratando de reflejar con ellos la pronunciación característica de las hablas andaluzas. Galeote pone distintos ejemplos, como la utilización de la letra $h$ - inicial para indicar aspiración ( habado o hamacuco, también con las entradas jabado y jamacuсo) o el empleo de la grafía $j$ - inicial para señalar igualmente aspiraciones (jambrera 'con hambre', jarnero o jartada). A juicio de Galeote, «la ortografía del Vocabulario andaluz ocasiona una alteración, distorsión o confusión de los datos inventariados» (p. 25).

En el apartado 2.2. se lleva a cabo una aproximación a las ilustraciones que contenía la primera edición del Vocabulario. Según indica Galeote, la obra consta únicamente de 173 ilustraciones, distribuidas muy desigualmente entre las letras (no todas) del abecedario: el $43 \%$ de ellas se concentra en las letras C (38), B (20) y A (17). Recordemos que la 6. ${ }^{a}$ base del Premio Conde de Cartagena decía así: «Sería de desear que en las voces técnicas las definiciones estuviesen acompañadas de dibujos o fotografías de los objetos definidos». La 
presencia de ilustraciones en esta primera edición del Vocabulario se explica, en efecto, por dicha base, pero nótese que en ella no se establecía como un requisito, sino como una opción del candidato que, naturalmente, sería valorada por los miembros del jurado. Galeote menciona algunas de las características de tales dibujos, que, a su juicio, son «ilustraciones con valor etnográfico» (p. 32); sin embargo, lamentablemente, no se detiene en cuestiones tan importantes como «la elección minuciosa que realizó de los temas ni por qué suprimió este material gráfico para la edición de la Real Academia Española (1951)» (p. 33).

Continuando con el estudio de las ilustraciones, el tercer apartado (pp. 34-46) se dedica a los lemas del Vocabulario que las contienen. Galeote asegura que en «el proyecto lexicográficodialectal de Alcalá Venceslada destaca la preocupación etnográfica y sus esfuerzos por describir la realidad material, la flora, la fauna y el entorno de la sociedad andaluza cuyo vocabulario intentaba recopilar» (pp. 35-36), de lo que colige el editor que, además de definir las voces, el lexicógrafo andujareño «comprobó que era necesario mostrar el objeto» (p. 36). Nuevamente, Galeote describe algunos rasgos de los dibujos («irregulares» en general y algunos, «más logrados»), que supone de la mano del propio compilador. Asimismo, en este subapartado (3.1. Palabras y cosas) se ofrecen al lector distintas tablas: una en la que se muestran las palabras de cada letra que presentan ilustraciones y otras donde se recogen las palabras ilustradas junto con su definición y el ámbito al que pertenecen (cultivo olivarero, albañilería, carpintería, etc.). Encabeza el subapartado 3.2. («Onomasiología y lexicografía») una tabla en la que se agrupan, según su pertenencia a distintos ámbitos, los artículos con ilustraciones; dicha tabla permite observar que la mayor parte de los dibujos se «corresponden a herramientas, especialmente, del mundo agrícola y ganadero, de la herrería, carpintería y tonelería, así como de las artes de pesca» (p. 43). Entre otras consideraciones, en este apartado Galeote reflexiona sobre el tratamiento que dio Alcalá Venceslada a ciertos términos de oficios tradicionales y se centra en las voces propias de la tonelería y sus ilustraciones (bojo, colete, contramediano, chantel, jarel, etc.).

En las conclusiones (pp. 46-48), sin olvidar las carencias de la primera edición Vocabulario andaluz, se subrayan algunos de sus valores y se invita a profundizar en su estudio: «Tal vez ha llegado el momento de conocer mejor esta primera edición, tan rara en las bibliotecas y tan poco conocida y estudiada. Creemos que conviene calibrar mejor sus limitaciones y valorar al mismo tiempo la radiografía dialectal que nos ofreció a través de los incompletos y criticados datos recolectados en variadas fuentes escritas (textos costumbristas, folclóricos, narrativos, dramáticos, poéticos y periodísticos) o recogidos de viva voz de los informantes andaluces» (p. 47).

Además de la rareza de Vocabulario andaluz de 1933-34, lo que dificultaba en la actualidad su consulta, uno de los motivos principales que han alentado la publicación de esta obra se encuentra en el deseo de poner a disposición del público la única edición en que se reprodujeron las pequeñas ilustraciones, posiblemente realizadas por Alcalá Venceslada, que acompañan a un puñado de definiciones. En la portada (y en la camisa) de la presente edición Galeote se encarga de subrayar este hecho incluyendo en el título, entre paréntesis, la palabra ilustrado, palabra que, naturalmente, no estaba en la obra de 1933-34. Lo cierto es que seguimos sin conocer la causa que aconsejó la eliminación de los dibujos en la edición de 1951, aunque quizá debería hablarse de varias causas. Repetimos que la utilización de dibujos no era un requisito en la convocatoria del Premio Conde de Cartagena. Ya en la primera edición la presencia de ilustraciones es, además de desigual entre las letras, muy escasa (173 dibujos en las 4245 entradas, es decir, tan solo un $4 \%$ de los artículos); este hecho, junto con el aumento notable 
de las entradas en la segunda edición, debieron de desaconsejar seguir ilustrando algunas definiciones. Además, es posible que el benemérito autor del Vocabulario concluyera que no merecía la pena el enorme esfuerzo de hacer tales dibujos cuando el producto lexicográfico de la Academia que finalmente se podría beneficiar del repertorio de andalucismos era el diccionario usual, una obra que, a diferencia del Diccionario manual, prescindía de ilustraciones.

Otro de los motivos que justifican la oportunidad de la reimpresión facsimilar llevada a cabo por Galeote atañe al estudio histórico del léxico español. Cuando consultamos una obra lexicográfica, lo habitual es manejar su última edición, puesto que esta suele superar a la anterior o anteriores en distintos aspectos, como, por ejemplo, el número de voces inventariadas. Esto, en efecto, es lo que sucedió con el Vocabulario andaluz de 1951, que aumentó considerablemente el caudal de voces respecto de la primera edición. Lo natural, en este caso, es consultar la segunda edición, preferiblemente la que corrió a cargo de Ahumada Lara. Ahora bien, para los historiadores del léxico también tiene su importancia manejar la edición de 1933-34. En el prólogo que encabeza la nueva edición que nos brinda el profesor Galeote, Álvarez de Miranda recuerda lo siguiente: «Téngase en cuenta que a los efectos de la lexicografía histórica no tiene el mismo valor que un vocablo o una acepción se documenten en 1951 o en 1934. Arañar en la cronología esos diecisiete años hacia atrás puede tener su interés» (pp. 7-8). Desde luego que importan esos años. Es sabido que, cuando nos disponemos a trazar la historia de una palabra, es frecuente manejar, junto a las fuentes primarias (los mismos textos), fuentes secundarias o lexicográficas. Las entradas que se recopilaron para la primera edición del Vocabulario andaluz pasaron, naturalmente, a su segunda edición, que es hoy la más conocida, no solo por las ediciones a que nos hemos referido (1980, 1998 y 1999), sino también por figurar en el Tesoro léxico de las hablas andaluzas, compilado por Alvar Ezquerra (2000: 9, n. 1 y 22). Pues bien, es posible que una voz se feche en 1951 cuando el primer testimonio o único sea el que ofrezca dicho Tesoro, como ocurre, entre muchas otras, con las voces ajaharrar «Guarnecer $<$ un muro $>$ antes de enlucirlo» o andujeño «Andujareño. De Andújar (J.)»; sin embargo, tales voces ya se encontraban en la primera edición del Vocabulario y, en consecuencia, es 1933-34, y no 1951, la fecha que les corresponde según las fuentes lexicográficas disponibles. El Diccionario histórico de la lengua española (1960-96), con mejor criterio, manejó y distinguió las dos ediciones, la primera (citada en esta obra según la fecha de la portada, 1933) y la segunda (Madrid, 1951). Cuando una voz se registraba por primera vez en la segunda edición, era esta la que se citaba (cfr. abarrenado, abocachado, abrochado, abufanado, acafetar, acelguilla, acojaccionar, acurdelarse, ansareta, etc.). Ahora bien, cuando la voz se encontraba en la primera edición del Vocabulario, el DHLE recogía esta por cuestiones cronológicas obvias: era la fecha más temprana de documentación lexicográfica. De este modo, en el artículo abocardador leemos: «m. Andal. "Instrumento para abocardar tubos de plomo." (Alcalá Venceslada VAndaluz 1933.) Ibíd.: Dame el abocardador para ensanchar este tubo.» (cfr. abajado, abarradera, abina, acarnerar, acerquillar, achichonado, acoquino, agriales, andrehuela, etc.). Nótese, además, que, a diferencia de lo que hizo el Tesoro de Alvar Ezquerra, el DHLE no solo aprovechó los valiosos ejemplos de uso que le proporcionaba el Vocabulario andaluz, sino muchas de sus citas textuales, como ocurre, por ejemplo, en agilioso: «adj. Andal. Ágil. 1909 MUÑOZ, EDUARDO José el Cabezota (Alcalá Venceslada VAndaluz $1951 \mathrm{~s} / \mathrm{v})$ : Estaba, como entonces, fuerte, agilioso, valiente. 1951 aLCALÁ VENCESLADA VAndaluz» (cfr. adeñir, afianzador, afinado , agalla, agrar, aguaceba, etc.).

Debemos aplaudir, en consecuencia, el afán del profesor Galeote por recuperar los primeros trabajos de la lexicografía andaluza; ya lo hizo en 2007 con el repertorio de Toro 
y Gisbert y en esta ocasión le ha tocado el turno al primer Vocabulario andaluz de Alcalá Venceslada. Como se ha dicho, el estudio preliminar de esta edición proporciona, basándose en algunos de los estudios más relevantes que se han ocupado de la obra, una visión de conjunto de las características del Vocabulario andaluz y las circunstancias históricas en que se gestó. Además, esta reimpresión facsimilar permite recuperar al curioso lector aquellos pequeños dibujos con los que se ilustró un puñado de definiciones. Finalmente, hay que subrayar el valor, a nuestro juicio, más importante de esta edición, y es que gracias a ella el estudioso del léxico dispondrá de una herramienta más, de no poca relevancia, con la que datar oportunamente algunos andalucismos.

\section{BIBLIOGRAFÍA}

Ahumada Lara, Ignacio (1986): «Sobre el Vocabulario andaluz de Alcalá Venceslada», Thesaurus. Boletín del Instituto Caro y Cuervo, XLI, 1, 2 y 3, pp. 135-154. [Reproducido en Boletín del Instituto de Estudios Giennenses, 129 (1987), pp. 83-99].

Ahumada Lara, Ignacio (2000): «Las aportaciones léxicas del vocabulario andaluz al DRAE», en Estudios de lexicografía regional del español, Jaén, UNED, pp. 51-73. [Reproducido en Jerónimo de las Heras Borrero et al. (eds.), Estudios sobre la modalidad lingüística andaluza en el aula, Huelva, J. Carrasco, 2001, pp. 11-44].

Alcalá Venceslada, Antonio (1933-1934): Vocabulario andaluz, Andújar, La Puritana. [1933 en portada y 1934 en cubierta y colofón; 407 pp.].

Alcalá Venceslada, Antonio (1951): Vocabulario andaluz, [2. ${ }^{\mathrm{a}}$ ed.], Madrid, Real Academia Española. [676 pp.].

Alcalá Venceslada, Antonio (1980[1951]): Vocabulario andaluz, Madrid, Gredos. [Reproduce la 2. ${ }^{\text {}}$ ed., 1951].

Alcalá Venceslada, Antonio (1998[1951]): Vocabulario andaluz, estudio preliminar y edición de Ignacio Ahumada, Jaén, Universidad de Jaén/CajaSur. [Reproduce la 2. ${ }^{a}$ ed., 1951, y contiene un «Anexo de más de setecientas autoridades literarias inéditas recogidas por el autor»].

Alcalá Venceslada, Antonio (1999[1951]): Vocabulario andaluz, Barcelona, Unidad Editorial. [Edición «de distribución conjunta e inseparable» del diario El Mundo. Andalucía; contiene el epílogo «El Vocabulario andaluz y su tiempo», de Ignacio Ahumada, pp. 681-688].

Alvar Ezquerra, Manuel (2000): Tesoro léxico de las hablas andaluzas, Madrid, Arco/Libros.

Carriscondo Esquivel, Francisco Manuel (2001): «El Vocabulario andaluz (1934), fuente de los andalucismos del DRAE (1936/1947)», Nueva Revista de Filología Hispánica, XLIX, 2, pp. 475492.

Carriscondo Esquivel, Francisco Manuel (2004): «El Vocabulario andaluz (1951), fuente de los andalucismos del DRAE (1970)», Nueva Revista de Filología Hispánica, LII, 1, pp. 107-142.

Garriga Escribano, Cecilio y Francesc Rodríguez Ortiz (2007): «1925-1927: del Diccionario usual y del Diccionario manual», Boletín de la Real Academia Española, LXXXVII, pp. 239-317.

Real Academia Española (1925): Diccionario de la lengua española, 15. ${ }^{\text {a }}$ ed., Madrid, Calpe.

Real Academia Española/Seminario de Lexicografía (1960-1996): Diccionario histórico de la lengua española; t. I (a-alá), Madrid, 1972; t. II (álaba-antígrafo), 1992; t. III, fasc. 1. ${ }^{\circ}$ (antigramaticalaonio), 1993, y fasc. 2. ${ }^{\circ}$ (aonio-apasanca), 1996; t. IV, fasc. 1. ${ }^{\circ}$ (b-bajoca), 1996. [Publicado el primer fascículo en 1960].

Toro y Gisbert, Miguel de (1920): «Voces andaluzas (o usadas por autores andaluces) que faltan en el Diccionario de la Academia Española», Revue Hispanique, XLIX, 116, pp. 313-647. [Existe edición facsimilar con estudio preliminar de Manuel Galeote, Lausana/Zaragoza, SSEH/Pórtico (Hispanica Helvetica, 17), 2007]. 